\title{
Article \\ A Methodology for the Comparative Analysis of Hybrid Electric and All-Electric Power Systems for Urban Air Mobility
}

\author{
Teresa Donateo *(D) and Antonio Ficarella (D) \\ Department of Engineering for Innovation, The University of Salento, via per Monteroni, 73100 Lecce, Italy; \\ antonio.ficarella@unisalento.it \\ * Correspondence: teresa.donateo@unisalento.it
}

\begin{abstract}
The present investigation addresses the topic of Urban Air Mobility with particular reference to the air-taxi service with electrified power systems. A new and detailed methodology is proposed for the simplified design and energy analysis of conventional, hybrid-electric, and fullelectric power systems for this application. The original contributions to the scientific literature on UAM are the detailed modeling approach, the evaluation of $\mathrm{CO}_{2}$ emissions with a Well-to-Wing approach as a function of the electricity Emission Intensity factor, and the comparison with road vehicles performing the same route in different driving conditions. The comparison demonstrates the advantages of a full electric air-taxi with today's technology versus a hybrid-electric road taxi, especially in cases involving low emission intensity and unfavorable driving conditions (congested traffic, aggressive driving style, and high circuity factor values). In the case of 2035 technology, the comparison with a referenced fully electric road vehicle is detrimental to the air taxi but the values of Well-to-Wheel/Wing $\mathrm{CO}_{2}$ with the expected Emission Intensity of $90 \mathrm{~g} / \mathrm{kWe}$ for the European Union are still quite low $(67 \mathrm{~g} / \mathrm{km})$. The investigation also quantifies the negative effect of battery aging on the consumption of the air taxi and on the number of consecutive flights that can be performed without fully charging the battery.
\end{abstract}

Citation: Donateo, T.; Ficarella, A. A Methodology for the Comparative Analysis of Hybrid Electric and All-Electric Power Systems for Urban Air Mobility. Energies 2022, 15, 638. https://doi.org/10.3390/en15020638 Academic Editors: Laura Tribioli, Manfredi Villani and Tek Tjing Lie

Received: 10 December 2021

Accepted: 13 January 2022

Published: 17 January 2022

Publisher's Note: MDPI stays neutral with regard to jurisdictional claims in published maps and institutional affiliations.

Copyright: (C) 2022 by the authors. Licensee MDPI, Basel, Switzerland. This article is an open access article distributed under the terms and conditions of the Creative Commons Attribution (CC BY) license (https:// creativecommons.org/licenses/by/ $4.0 /)$.

\section{Introduction}

According to Angel et al. [1], the number of people living in cities keeps growing and is expected to double from 2011 to 2054. This increase in the mobility requirement is leading to the need for faster, cheaper, safer, and cleaner forms of transportation [2], not only to avoid the depletion of fossil energy sources but above all to preserve the environment. Transportation accounts for around one-fifth of today's global carbon dioxide $\left(\mathrm{CO}_{2}\right)$ emissions [3]. Road travel accounts for three-quarters of them, while the contribution of aviation to transport-associated emissions is $11.6 \%$. Increasing the efficiency of the utilization of energy in transport systems, speeding up the deployment of sustainable energy sources, and enhancing zero-emission vehicles are the main actions that have been proposed to reduce the environmental impact of transportation [3] and fulfill future mobility requests.

In the last few years, many companies have developed delivery and taxi services conceived to work in the air. These new services are denoted as Urban Air Mobility (UAM) and Urban Air Delivery. This investigation focuses on Urban Air Mobility and, in particular, on the air-taxi service. In this field, several companies have developed electric vertical take-off and landing (eVTOL) aircraft over the past few years. However, there are still many open issues such as the lack of infrastructure, the need to ensure safety (in particular avoiding collisions during the mission), and the development of suitable air-traffic management systems [4-6].

UAM is an appealing application for electric power systems thanks to its short-range and limited speed requirements that make full electric powertrains possible, even with 
today's batteries (i.e., despite their moderate values of energy density and power density, which are the major bottlenecks for larger aircraft). For longer distances, hybrid-electric concepts can be considered to provide the necessary range while guaranteeing silent and environmentally friendly transport systems. To ensure the success of electric and hybrid-electric air taxis, an extensive charging infrastructure powered by clean energy sources is needed as well as the availability of a large number of take-off and landing facilities [7]. Moreover, ad hoc flight mechanics analysis tools and design techniques need to be developed to tackle the challenge of sizing and management of hybrid and fully electric aircraft. In fact, the analysis of the energy request of this kind of vehicle and their environmental impact is a hot topic still in need of further research efforts, as proved by the limited works in this topic, such as the recent studies on Urban Air Delivery [8-10] and UAM [11-14].

Uber [11] performed a comparison between a traditional road vehicle and a VTOL one in terms of time spent, distance covered, and costs without considering the environmental impact. As pointed out in [12], the sustainability of air-taxi services is unclear because of the high energy requirement of this kind of vehicle, above all for take-off and climb. A comprehensive review of the research on UAM is presented in [15], where the development of more refined and high-fidelity models is suggested as one of the potential research directions in this field. This work also points out the importance of taking into account the largest safety allowed by the hybrid-electric power systems in rotorcraft thanks to the possibility of performing safe descents after an engine/motor failure.

The authors of [14], proposed a comparison of the Greenhouse Gas (GHG) emissions of a VTOL over a distance of $100 \mathrm{~km}$ versus ground-based passenger cars and, in particular, a conventional internal combustion engine vehicle and a battery-electric vehicle. However, this work performs a simplified analysis: the part-load efficiency of the powertrain and the large variability of energy consumption of a road vehicle due to the effect of the traffic conditions are not taken into account. The different effects of traffic conditions and weather on the travel time of road and aerial vehicles are addressed in [12] where it is also pointed out that the travel time of a VTOL is much more predictable than that of a road vehicle.

A similar but more detailed analysis is performed in [16], in which the authors developed a model to quantify trip emissions using UAM and compared them with automotivebased trips. The authors of this study consider gasoline and electric vehicles as automotive technology and calculate the emissions associated with electricity production using the emission factor of the metropolitan area of Chicago and Dallas. Moreover, this work proposes the detour ratio (defined as the distance saved or gained by using an aerial vehicle instead of a road vehicle driving the same route) as a metric to compare air and road transportation while the circuity factor (the ratio of the shortest road route to the Euclidian distance) is proposed in [12] to compare air and road vehicles.

The present work differs from $[12,16]$ in the following aspects that constitute its novel contribution to the scientific literature on UAM:

- The UAM is modeled with a detailed approach for the battery that takes into account non-linear and aging effects and part-load efficiencies for the engine and the motor.

- Different powertrains (conventional, fully electric, and parallel hybrid electric) are considered for the air taxi and the role of energy management is addressed in the case of the hybrid electric powertrain.

- The emissions associated with the battery charging are calculated as a function of emission intensity of the electricity production, with particular reference to the European Union.

- The road vehicles considered in this investigation are different for today and 2035 technology and are analyzed under favorable and unfavorable driving conditions (in terms of traffic congestion, driving style, and circuity factor).

- The performances of the electrified air taxis are evaluated with the battery at the start and the end of its life. 
- The environmental impact is assessed with a new well-to-wing/wheel approach per $\mathrm{km}$ of straight or Euclidean distance between the initial and final place of the emission (i.e., taking into account different values of the circuity factor for the road vehicles).

A more complete analysis of the environmental impact of road and air vehicles should be performed at the cradle-to-grave emissions level [16], i.e., taking into account all processes from the extraction to the discarding of materials (thus including production, operation, and disposal phases). However, this is beyond the scope of this investigation.

After this first introductory section, the present paper is organized as follows. The second section depicts the simplified sizing of the aerial vehicles and their specification. The third part describes the proposed detailed methodology for the energy analysis of aerial vehicles. Then, the road vehicles used for the comparison are presented and the procedure for the evaluation of the environmental impact is explained in session 5. Finally, the results for today and 2035 technologies are discussed, and the conclusions are drawn.

\section{Simplified Sizing of the Air-Taxis}

A hypothetical four-passenger vertical take-off and landing (VTOL) rotorcraft with co-axial rotors is considered as air taxi architecture. This is in line with the works proposed in the literature; see, for example [12,17], in which electric VTOL vehicles with four to five occupants are considered for UAM.

In this work, three different power systems are proposed and compared: conventional (turboshaft-based powertrain), full electric (Lithium-ion battery and permanent magnet motors), and parallel hybrid electric (combining the previous technologies). The evaluation of the air-taxi mass in the three cases is not a trivial issue and depends on the present-day and future values for specific power and density of the main components [18-25]. The goal of the investigation is to propose a methodology for the energy analysis of a complex power system for UAM, not to analyze a particular technology. However, it is interesting to point out the strong expected improvement in the components of an electrified power system and to show how this affects the results of the proposed methodology. For this reason, the data retrieved in the scientific literature for today and future (2035) technologies (Table 1) were assumed for the turboshaft engines, the electric machines (and their inverter), and the battery. The potential different contribution of the gearbox to the weight of the proposed powertrains is neglected for simplicity.

Table 1. Current and future values of specific power and energy densities ([19,25]).

\begin{tabular}{ccccc}
\hline Component & Specification & Unit & Today & 2035 \\
\hline Turboshaft engine & Specific Power & $(\mathrm{kW} / \mathrm{kg})$ & 4.3 & $7.7-11$ \\
Inverter & Specific power & $(\mathrm{kW} / \mathrm{kg})$ & 2.2 & $9-19$ \\
Electric machine & Specific power & $(\mathrm{kW} / \mathrm{kg})$ & 2 & $9-16$ \\
Lithium battery & Power Density & $(\mathrm{W} / \mathrm{kg})$ & 520 & $745-1200$ \\
Lithium battery & Specific Energy & $(\mathrm{Wh} / \mathrm{kg})$ & 144 & $250-400$ \\
\hline
\end{tabular}

It is important to mention the relation between battery power density and energy density. The values of Table 1 are related to batteries optimized for energy density (this is the normal choice for a fully electric system), but the design of a Lithium-ion battery can be aimed at optimizing the power density at the expense of energy density or vice versa [26]. The power density of a battery mainly depends on its $C_{\text {rate }}$, i.e., the maximum current at which the battery can be discharged, termed as a multiple of the battery nominal capacity [26]. In fact, the nominal continuous power $\left(P_{b a t t, n o m}\right)$ of a Lithium-ion battery in discharge can be expressed as:

$$
P_{\text {batt }, \text { nom }}=C_{\text {rate }} \cdot C_{\text {nom }} \cdot N s \cdot V_{\text {cell }}
$$

where $C_{\text {nom }}$ is the nominal capacity (in $\left.\mathrm{Ah}\right), V_{\text {cell }}$ is the nominal voltage of a Lithium-ion cell $(3.6 \mathrm{~V})$, and $N s$ is the number of cells in the series. Assuming a nominal voltage of 
$270 \mathrm{~V}$ for the battery pack $\left(N s \cdot V_{c e l l}\right)$, as suggested by Bérubé et al. [20], it is easy to verify that the values in Table 1 refer to a battery with a continuous $C_{\text {rate }}$, ranging between 3 and 4 , but higher values of the $C_{\text {rate }}$ can be obtained even with today's technology [21] and without significantly penalizing the energy density. It should also be noted that, for a short interval of time compatible with the duration of the take-off (about $30 \mathrm{~s}$ ), the battery can be operated at a current higher than $C_{\text {rate }}$ which is named burst $C_{\text {rate }}$ and is generally equal to $2 C_{\text {rate }}[24,26]$.

To obtain realistic specifications for the UAM powertrains, the following procedure is proposed here for fast preliminary sizing:

1. The empty mass is initially assigned equal to $1000 \mathrm{~kg}$.

2. A payload of $360 \mathrm{~kg}$ is added in all cases to account for four passengers (including luggage) and a reserve of $50 \mathrm{~kg}$ of fuel is considered for the conventional and hybrid electric powertrains.

3. For each of the configurations considered in this work (conventional, parallel hybrid electric, and fully electric), a tentative value is assigned to the size of the components (nominal power for the energy converters, energy content for the battery).

4. Using the data of Table 1, the take-off mass of the powertrain is estimated for current and 2035 technology.

5. The empty weight is upgraded to keep the ratio of empty-to-take-off mass equal to $0.6[14]$.

6. The take-off weight is used to estimate the take-off power. If this cannot be achieved with the proposed powertrain, the size of the converters is increased.

The iteration is terminated when the convergence on the empty mass is reached.

The take-off power is calculated as suggested in the literature $[12,16]$ for VTOL vehicles by using the formula for the power request in hover:

$$
P_{\text {hover }}=\frac{M g}{\eta_{p}} \sqrt{\frac{\delta}{2 \rho_{a}}}
$$

where $\delta$ is the disk loading and $\rho_{a}$ is the sea-level air density $\left(1.22 \mathrm{~kg} / \mathrm{m}^{3}\right), \mathrm{g}$ is the gravity acceleration. For all the powertrains, a value of 0.85 was assumed for the propulsive efficiency [16] and the disk loading was set to $380 \mathrm{Nm}^{-2}[16,27]$.

The results of the procedure are shown in Figure 1, Tables 2 and 3 in terms of final take-off mass and powertrain specifications.

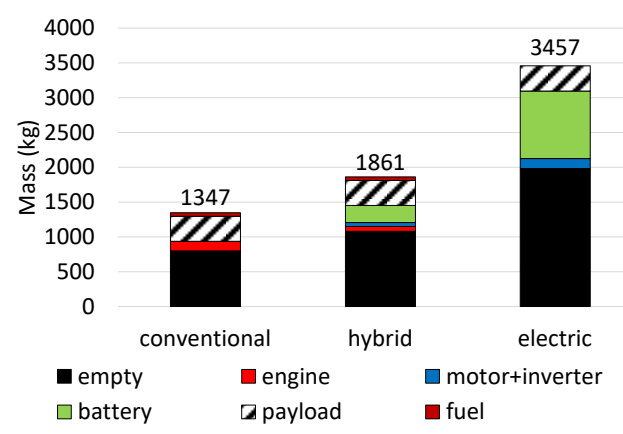

(a)

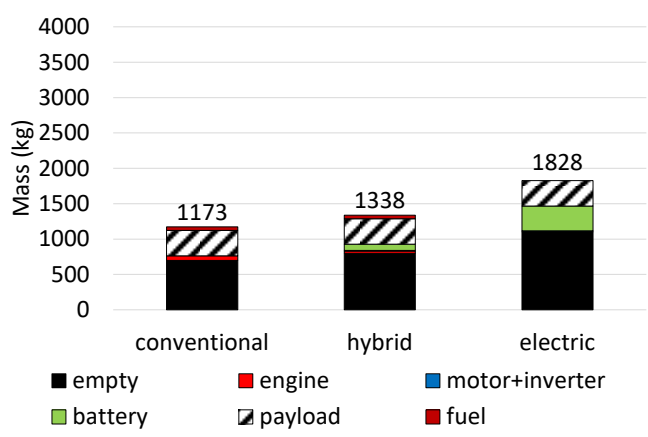

(b)

Figure 1. Estimated take-off mass (in $\mathrm{kg}$ ) of the proposed powertrain for the aerial taxi. (a) Today's technology; (b) 2035 technology. 
Table 2. Specification of today's powertrains.

\begin{tabular}{cccc}
\hline & Conventional & Hybrid & Electric \\
\hline Engine size & $2 \times 295 \mathrm{~kW}$ & $295 \mathrm{~kW}$ & - \\
Motor size & - & $3 \times 120 \mathrm{~kW}$ & $5 \times 120 \mathrm{~kW}$ \\
Battery size & - & $35 \mathrm{kWh}$ & $140 \mathrm{kWh}$ \\
Battery capacity (Ah) @ 270 V & - & 130 & 520 \\
Take-off power (kW) & 194 & 268 & 498 \\
Required battery C rate $(@ 270 \mathrm{~V})$ & - & 8 & 4 \\
\hline
\end{tabular}

Table 3. Specification of the 2035 powertrains.

\begin{tabular}{cccc}
\hline & Conventional & Hybrid & Electric \\
\hline Engine size & $2 \times 295 \mathrm{~kW}$ & $295 \mathrm{~kW}$ & - \\
Motor size & - & $2 \times 120 \mathrm{~kW}$ & $4 \times 120 \mathrm{~kW}$ \\
Battery size & - & $35 \mathrm{kWh}$ & $140 \mathrm{kWh}$ \\
Battery capacity (Ah) @ 270 V & - & 130 & 520 \\
Take-off power (kW) & 169 & 193 & 263 \\
Required battery C rate @ 270 V & - & 6 & 2 \\
\hline
\end{tabular}

Regarding the take-off mass (Figure 1) the largest contribution of the powertrain to the take-off weight is associated with the battery, especially in the case of today's technology and fully electric aerial vehicles. It should also be noted that, at constant mass, the 2035 technology allows a designer to shift from conventional to hybrid (with about $1350 \mathrm{~kg}$ ) and from hybrid to electric (accepting a take-off weight of about $1850 \mathrm{~kg}$ ).

Regarding the installed power, in the conventional case, we considered a twin-engine configuration to allow safety in case of failure. The size of $295 \mathrm{~kW}$ (400 HP) was chosen according to the specification of the Hill GT500 engine [22]. Since it is difficult to scale down a turboshaft engine, the same nominal power was also considered for the 2035 technology. For the motors, we opted for modules of $120 \mathrm{~kW}$ since more powerful electric machines for aerospace applications are still under development [23]. The number of modules $\left(N_{E M}\right)$ was chosen so that the take-off could be performed with $\left(N_{E M}-1\right)$ motors. The size of the battery was set equal to 35 and $140 \mathrm{~kW}$ for the hybrid and the full-electric case, respectively, based on the experience of the authors and with a trial-and-error procedure on the mission analysis described later in the paper.

For the hybrid electric taxi, take-off can be performed in thermal, electric, or power-assist modes. Since it is also necessary to guarantee that the battery can feed the motors in case of electric take-off, the minimum continuous $C_{\text {rate }}$ required for the battery in the different cases was estimated and entered in Tables 2 and 4 . Based on the previous discussion about the typical continuous and burst $C_{\text {rate }}$ of today's battery, we can conclude that the battery is able to guarantee an electric take-off in all cases reported in Tables 2 and 3.

Table 4. Other specifications of the air taxis $([14,16])$.

\begin{tabular}{cccc}
\hline & Conventional & Hybrid & Electric \\
\hline Today's $L / D$ & 6.21 & 7.32 & 5.98 \\
$2035 L / D$ & 12 & 12 & 12 \\
\hline
\end{tabular}

As a partial validation of the sizing procedure, it is possible to notice that the take-off mass obtained for the 2035 electric air taxis is very close to the value of $4000 \mathrm{lbs}$ assumed in [11] for a UAV powered by a battery with $400 \mathrm{kWh} / \mathrm{kg}$. However, the goal of this first step was not to propose a detailed sizing methodology but to obtain reasonable values for the take-off weights of the three powertrains to allow a fair comparison in terms of energy and power request. 


\section{Proposed Methodology for the Air-Taxi}

Once the powertrain was defined, the energy and fuel consumptions were calculated with the procedure here explained and illustrated in Appendix A (Figure A1) for the hybrid propulsion system. Note that the fully electric and conventional powertrains can be considered as particular cases of this complex power system.

The simulations proposed in this investigation were performed with a quasi-static approach. Each mission was divided into intervals of time length $h$ and, at any time step, the components of the power system were assumed to work in stationary conditions even if the working point was different at each time step. Such an approach is generally accepted in the minimization of fuel consumption in complex powertrains [26] because it allows the design of a supervisory controller to optimize the power flows in the propulsion system with a small computational effort. However, this approach requires the mission to be known a priori and is not able to handle feedback control problems or to take into account the dynamic response of the energy converters to a variable power request that affects the shaft dynamic in a rotorcraft or the dynamic behavior of the fuel valve [28]. A dynamic model of the whole power system, including the twin rotors, is currently being implemented by some of the authors of this investigation and preliminary results can be found in [29]. Note that a dynamic approach would be able to take into account other factors, such as the effect of temperature on each component of the power system, that are neglected in this investigation.

\subsection{The Route (Start and Final Points)}

The vehicles are supposed to perform the same hypothetical route which corresponds to a total straight-line or Euclidean distance of $70 \mathrm{~km}$. When comparing air-taxi and groundbased transportation systems, it is necessary to take into account the circuity factor, i.e., the ratio between actual road travel distance and coordinate-calculated Euclidean distance. A circuity factor of 1.2 is considered in [30] for the comparison between air and road vehicles. However, this value is strongly variable from country to country, as pointed out in [18] where an average circuity factor of 1.46 is reported for Europe.

It is important to point out that the trip time of the road taxi is strongly affected by driving style, weather, and traffic conditions. Headwinds or tailwinds, on the other hand, do not change the true airspeed (TAS) of the aerial vehicle even if they affect the groundspeed. However, frequent back and forth along a given air-taxi route would likely balance these changes [12].

\subsection{Mission Profile and Flight Dynamics}

Based on the white paper of Uber [11], a typical mission was considered, consisting of take-off, climb, cruise, descent, and landing. The proposed mission was characterized by a cruise altitude of $458.6 \mathrm{~m}$ and a cruise speed of $67 \mathrm{~m} / \mathrm{s}(150 \mathrm{mph})$; as suggested in [11,27] the $R O C$ (Rate of Climb) and ROD (Rate of Descent) were assumed equal to $2.54 \mathrm{~m} / \mathrm{s}$ $(500 \mathrm{ft} / \mathrm{min})$ in the present investigation.

The shaft power request vs. time was estimated using literature methods and data $([16,27])$. For the vertical take-off and landing, the power request was calculated as in Equation (2).

At cruise conditions:

$$
P_{\text {cruise }}=\frac{M g}{L / D} \frac{V}{\eta_{p}}
$$

For climb and descent:

$$
\begin{gathered}
P_{\text {climb }}=\frac{M g}{\eta_{p}}\left(R O C+\frac{V}{\frac{L}{D}}\right) \\
P_{\text {descent }}=\frac{M g}{\eta_{p}}\left(R O D+\frac{V}{\frac{L}{D}}\right)
\end{gathered}
$$


In these equations, $M$ is the take-off mass of the vehicle and $V$ is the true airspeed. The values of the propulsive efficiency $\eta_{p}$ used in this investigation are reported in Table 2. The powertrain efficiency is included in the denominator of these formulas in the approach proposed in [16], while in the present investigation, $\eta_{p}$ in Equations (2)-(5) is only the propulsive efficiency (i.e., the efficiency of the rotor) while the powertrain efficiency is calculated with the detailed model explained below.

It is also necessary to point out that in the conventional and hybrid-electric powertrains, the mass of the vehicle decreases in time due to the consumption of fuel. Even if this effect can be easily implemented in the proposed procedure, it is not considered here because the amount of fuel consumed in the reference mission was much smaller than the take-off mass of the vehicle, as shown later. Note that the total power requirements for VTOL flight include the additional power drawn from auxiliary systems such as avionics or passenger comforts (heating/cooling, phone charging, radio, etc.). As suggested in [16], these contributions are neglected in this investigation.

The time histories of the shaft power request for the three powertrains (according to their different masses) are reported in Figure 2.

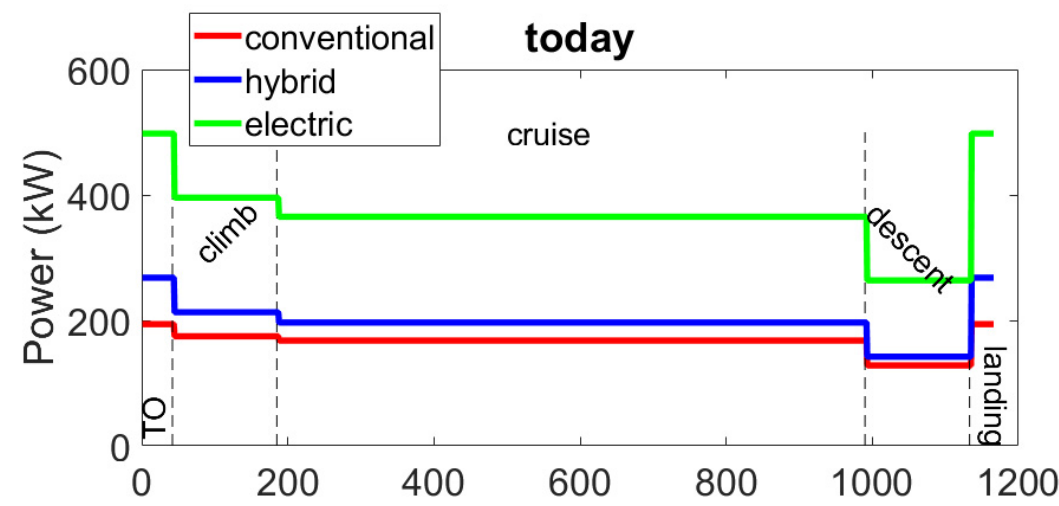

2035

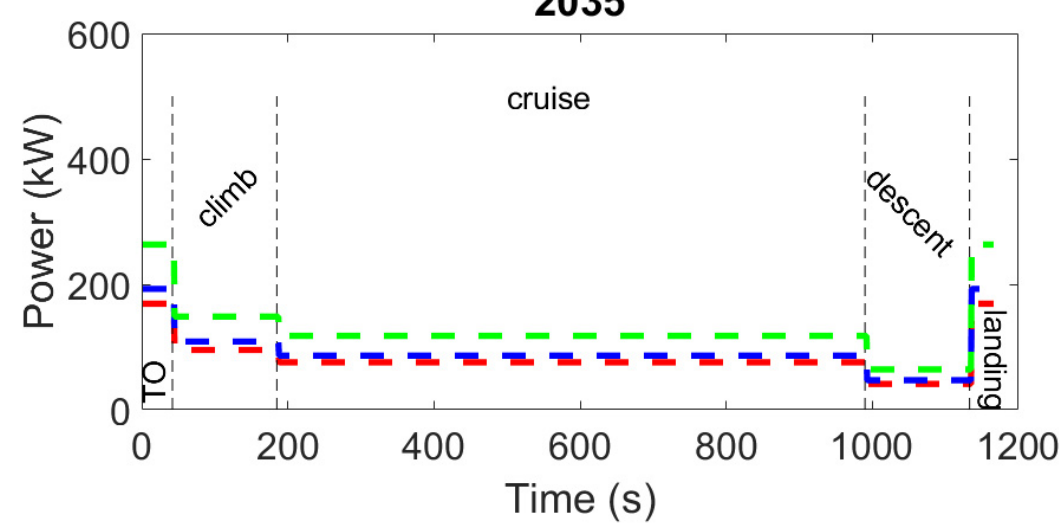

Figure 2. Power request of the three configurations with current and 2035 technology.

\subsection{Simulation of the Energy Flows}

The missions of Figure 2 were discretized with a time step of $1 \mathrm{~s}$. At each time step, the required shaft power was used as input to the detailed model of the power system.

In the conventional case, the power shaft request is fulfilled by the engine. In the electric case, it is fully developed by the electric machines. For the hybrid electric powertrain, an appropriate energy management strategy must be defined because it can be operated in four different modes:

- Thermal mode: the electric drive is not used and the power request is entirely satisfied by the engine. 
- Electric mode: the engine is turned off (or in failure) and the power request is fulfilled by the electric drive.

- $\quad$ Power-assist mode: both the electric machines and the engine give power to the shaft.

- On-flight charge mode: the turboshaft engine is used to meet the power request and to charge the battery during the flight.

Note that the on-flight charge mode was not implemented in this work because it was found to be of little utility in the case of air vehicles [31]. All the other modes can be obtained with a specific value of the control parameter $u$, which is defined here as:

$$
u(h)=\frac{P_{E M}(h)}{P_{E M, n o m}}, \text { with } 0 \leq u \leq 1
$$

where $P_{E M, n o m}$ is the nominal power of the electric machine, and $P_{E M}(h)$ is the contribution of the electric machine at time step $h$. Therefore, the power to be delivered by the thermal engine, $P_{i c e}(h)$, is:

$$
P_{\text {ice }}(h)=P_{\text {shaft }}(h)-P_{E M}(h)
$$

Note that the denominator in the expression of the control variable $u$, Equation (6), should be the minimum between the nominal power of the electric motors and the available battery power. However, it has been already verified that the battery can satisfy the take-off power with reasonable values of the $C_{\text {rate }}$. Similarly, $P_{i c e}(h)$ should be compared with the maximum power of the engine at the flight altitude $z(h)$ to ensure that the engine is able, at any moment, to satisfy the request. Since the engine is quite oversized (see Tables 2 and 4) and the other phases of the flight require much less power than take-off and landing (see Figure 2), this constraint is easily met.

In the authors' previous investigation [31], the ECMS (equivalent consumption minimization strategy) was proposed for a similar application to calculate the optimal $u(h)$. The Equivalent Consumption Minimization Strategy [26] considers the battery as an auxiliary fuel tank and converts its electrical energy into virtual fuel consumption. The virtual and actual fuel flow rates are combined to obtain the instantaneous equivalent fuel consumption in the following way:

$$
\min \left(\dot{m_{e q}}\right)=m_{f}(h)+f_{e q} \cdot P_{\text {batt }}(h) \cdot f_{p}(h)
$$

where the equivalence factor $f_{e q}$ converts the battery power to a virtual fuel flow rate. The virtual fuel flow rate can be either positive or negative according to the sign of the battery power (battery charged or discharged). Thus, the equivalent fuel consumption can be higher or lower than the actual fuel consumption in the ECMS original strategy. The penalty factor $f_{p}$ is a correction that accounts for the divergence of the current SOC from the (constant) desired value of the battery state of charge $\left(S O C_{r e f}\right)$. In this investigation, the penalty factor $f_{p}$ is calculated according to the deviation of SOC at timestep $h$ from a reference curve $S O C_{r e f}(h)$ :

$$
\begin{gathered}
x(h)=\frac{\operatorname{SOC}(h)-\operatorname{SOC}_{r e f}(h)}{\operatorname{SOC}_{r e f}(h)} \\
f_{p}(h)=(1+|x|)^{p}
\end{gathered}
$$

The optimal values of $f_{e q}$ and $p$ were obtained in a previous work [31].

According to the results of [31], we selected a reference SOC curve that decreases linearly over time, except in cruise where it is kept constant (the battery is not used).

During each simulation run with the proposed strategy, local optimization was performed at each time step $h$ of the mission, by considering all the values of $u$ ranging between 0 and 1 with a step of 0.1 and choosing the value of $u$ corresponding to the minimum of $\dot{m}_{e q}$. In other words, an enumerative optimization technique was used. However, other 
local search methods could have been used when the strategy was applied online in the UAM vehicle.

The ECMS has the main goal of minimizing fuel consumption during the mission. However other targets can be considered specifically for air-taxi operation. For this reason, we propose in this investigation a simple rule-based strategy aimed at reducing the environmental and acoustic impact of the hybrid-electric configuration during take-off and landing. To this scope, take-off and landing are performed in electric mode and cruise in thermal mode. The climb phase is performed in power assist mode (with $u=1$ ) until the SOC reaches a threshold value $(90 \%)$ to obtain the desired $S O C_{r e f}$ curve. The other phases of the flight are performed in thermal mode.

\subsection{Total Fuel Burn in the Mission $\left(M_{f}\right)$}

The total fuel burn is calculated starting from the $P_{i c e}(h)$ of the turboshaft engine with a simple empirical model, developed in a previous investigation [31]. The specific fuel consumption $\operatorname{SFC}(h)$ at each time step is estimated as:

$$
\frac{\operatorname{SFC}(h)}{S F C_{0}}=\left(\frac{\text { Pice }(h)}{\text { Pice, nom }}\right)^{b 2}\left(z_{1} Z(h)+z_{0}\right)\left(m_{2} M+m_{1} M+m_{0}\right)+b 1
$$

where $Z$ is the altitude (in meters) and $M$ is the Mach number (note that this effect is negligible for this application). Pice, nom, and $S F C_{0}$ are the shaft power and the specific fuel consumption of the engine at its design point, respectively. This equation contains seven parameters $\left(b_{1}, b_{2}, m_{0}, m_{1}, m_{2}, z_{0}, z_{1}\right)$ whose values were fitted in [31] by comparison with a detailed model of the engine.

The fuel flow rate is calculated as $m_{f} \cdot(h)=\operatorname{SFC}(h, j) \cdot P_{i c e}(h)$. By numerically integrating $m_{f} \cdot(h)$, the total fuel burn $M_{f}$ is obtained for the conventional and hybrid electric power system.

\subsection{Electric Consumption of the Mission $E_{\text {tot }}$}

The power contribution of the electric machines is used as input to calculate the electricity consumption. Each electric machine (inclusive of the driver) is modeled with a simple Willans line as proposed by [26] so that the battery current can be expressed as:

$$
P_{\text {batt }}(h)=\frac{P_{E M}(h)+P_{0}}{e}
$$

where $e$ is the intrinsic efficiency of the electrical-to-mechanical energy conversion process and $P_{0}$ accounts for the losses taking place after the energy conversion (friction, heat losses, etc.). In this investigation, we assumed $e=0.9$ and $P_{0}=1.4 \mathrm{~kW}$ as reported in [26] for permanent magnet machines.

The battery is simulated with an electric equivalent circuit [26]. The Open-Circuit Voltage $O C V$ is a function of the battery state of charge, while the internal resistance $R$ is considered independent of the SOC but related to the specification of the battery and varying along with the battery life. Therefore, the battery current is calculated by solving the following equation:

$$
P_{\text {batt }}(h)=[O C V(h)-R(t) \cdot I(h)] \cdot I(h)
$$

By integrating the battery power, the total electric consumption of the mission $E_{t o t}$ is obtained for the hybrid electric and full electric power systems.

The battery is also affected by the Peukert effect, i.e., the battery's actual capacity decreases when the discharge power is increased. To take into account this phenomenon, the effective current $I_{e f f}$ is calculated as:

$$
I_{\text {eff }}(h)=I(h) \cdot\left(\frac{I(h)}{I_{\text {nom }}}\right)^{n-1}
$$


where $n$ is the Peukert coefficient, $I_{n o m}$ is the current at which the nominal capacity of the battery is obtained.

Using the effective current, the state of charge is upgraded, at any time during the mission, as:

$$
\operatorname{SOC}(h)=S O C_{i n}-100 \cdot \sum_{1}^{N} \frac{I_{\text {eff }}(t)}{C}
$$

where $S O C_{i n}$ is the battery state of charge at the beginning of the mission. The Depth of Discharge (DOD) is calculated as the change between the initial and final SOC of the battery in each mission.

With this modeling approach, it is possible to take into account the increase in battery current at constant power due to the reduction in the SOC which, in turn, determines a reduction in the OCV. Another important characteristic of the proposed battery model is that the values of capacity, internal resistance, and Peukert coefficient are updated with the battery state of health. In particular, the values of these parameters at the beginning and the end of the battery life are shown in Table 5. For more details about the aging model, please refer to [32].

Table 5. Values assumed for the battery parameters.

\begin{tabular}{cccc}
\hline Battery Status & Capacity $($ Ah) & $\mathbf{R}_{\mathbf{i}}(\mathbf{\Omega})$ & $n$ \\
\hline New & $C_{\text {nom }}$ & $9.54 \mathrm{e}-5$ & 1.09 \\
\hline Aged (End of life) & $0.8 C_{\text {nom }}$ & $11.75 \mathrm{e}-5$ & 1.19 \\
\hline
\end{tabular}

The end of life for a vehicle drive battery is defined as the time when either the battery energy capacity or its available power (which is inversely proportional to the internal resistance) drop below a specified minimum, which is usually set equal to $80 \%$ of the initial value [33]. The time at which this condition is reached is the minimum between the cycle life (degradation due to repeated charge-discharge cycling) and the calendar life (degradation over time). Calendar and cycle life are affected by the battery operation, and in particular operating temperature, DOD, and charge/discharge current [34]. The dependence on DOD can be found in the datasheet provided by the battery manufacturer or estimated with the models proposed in the scientific literature (see for example [35,36]).

\section{Reference Road Vehicles}

The emissions of $\mathrm{CO}_{2}$ of the different powertrains for air taxi will be compared with those of a road vehicle performing the same mission. Recently, the European Commission revised the Regulation setting $\mathrm{CO}_{2}$ emission standards for cars and light commercial vehicles, reducing the target value by $37.5 \%$ in 2030 compared to the 2021 limit of $95 \mathrm{~g} \mathrm{CO}_{2} / \mathrm{km}$. However, this value refers to the whole fleet and only the Tank-to-Wheel emissions are considered. For a more detailed comparison, reference road vehicles are used in this investigation.

The vehicle used as an example of today's road technology is a well-known series/parallel hybrid electric vehicle, the Toyota Prius. The reason for the choice of this car is twofold: it is one of the most common vehicles used as a road taxi and is the most-studied hybrid electric vehicle (see, for example [37]). The Prius non-plug-in vehicle has a curb mass of $1470 \mathrm{~kg}$ and a declared fuel consumption of $4.8 \mathrm{~L} / \mathrm{km}$ over the New European Driving Cycle. However, tests performed on the same vehicle [38] revealed that the fuel consumption (FC) of the Prius can range between 3 and $6 \mathrm{~L} / 100 \mathrm{~km}$ on regulatory cycles (depending also on the version of the vehicle) while a still higher variability is obtained in real driving conditions [39] where the fuel consumption can be as high as $14.8 \mathrm{~L} / 100 \mathrm{~km}$ in case of urban routes and aggressive driving styles. Note that the curb mass of the Toyota Prius is $1350 \mathrm{~kg}$. By adding the same payload of the aerial vehicle $(360 \mathrm{~kg})$, a mass of 
$1710 \mathrm{~kg}$ is obtained, a value not much different than that of the hybrid electric air taxi with today's technology.

The fully electric Nissan Leaf was chosen as exemplative of 2035 road taxi because it is one of the most-studied electric vehicles and was also proposed for road-taxi services [40]. The Nissan Leaf has a range of $200 \mathrm{~km}$ and a nominal electric consumption of $0.17 \mathrm{kWh} / \mathrm{km}$ [41]. The expected improvement in technology for this kind of vehicle in 2035 is difficult to evaluate. For simplicity, we will assume that the expected increased energy density will allow the usage of a larger battery with the same mass. This will translate into a strong increase in range that will enhance the usage of vehicles as taxi service, but the energy consumption will be quite unchanged. Note that the electricity consumption must be corrected with the circuity factor, as in the case of the Toyota Prius, before performing the comparison with the aerial taxi. Moreover, the effects of traffic conditions and driving style are also to be considered [42]. For the Nissan Leaf, the study in [43] reports a value of $0.24 \mathrm{kWh} / \mathrm{km}$ in real driving conditions.

\section{Environmental Impact}

To compare the different vehicles from an environmental point of view, a Well-ToWheel/Wing approach is considered, i.e., the greenhouse emissions are calculated considering the whole process from the primary energy source (e.g., crude oil) to the final energy to the wheels/wings. Moreover, they are normalized to the Euclidean distance between the initial and final places of the mission. To this scope, for gasoline and kerosene, it is possible to assume $3.15 \mathrm{~kg} \mathrm{gO}_{2} / \mathrm{kg}_{\text {fuel }}$ for the Tank-to-Wheel conversion, and $0.55 \mathrm{~kg} \mathrm{CO}_{2} / \mathrm{kg}_{\text {fuel }}$ for the WTT. In other words, the WTT emissions account for $15 \%$ of the WTW contribution [44]. The grams of $\mathrm{CO}_{2}$ per $\mathrm{km}$ of Euclidean distance $(E D)$ of the aerial vehicle are calculated as:

$$
\mathrm{CO}_{2} \text {, thermal, aerial }=\frac{3.7 M_{f}}{1000 \cdot E D}
$$

where $M_{f}$ is expressed in $\mathrm{kg}$ and $E D$ in $\mathrm{km}$.

To account for the circuity factor, the WTW emissions of $\mathrm{CO}_{2}$ of the Toyota Prius per $\mathrm{km}$ of Euclidean distance are calculated as:

$$
\mathrm{CO}_{2} \text {, thermal, } \mathrm{road}=10 \cdot \mathrm{FC} \cdot \rho_{\text {gasoline }} \cdot \mathrm{CF} \cdot 3.7
$$

where $F C$ is the fuel consumption in $1 / 100 \mathrm{~km}, \rho_{\text {gasoline }}=0.755 \mathrm{~kg} / \mathrm{L}, \mathrm{CF}$ is the circuity factor, and $3.7 \mathrm{~kg} \mathrm{CO}_{2} / \mathrm{kg}_{\text {fuel }}$ is the WTW emission factor gasoline.

The contribution associated with the electricity for the aerial vehicles is linearly proportional to the amount of electricity released by the battery $\left(E_{t o t}\right)$. To account for the losses in the grid and at the charging station, an overall efficiency $\eta_{\text {charge }}$ is introduced and its value is set to $80 \%$ [45]:

$$
\mathrm{CO}_{2}, \text { elec, aerial }=E I \cdot \frac{E_{\text {tot }}}{\eta_{\text {charge }} E D} .
$$

where $E I$ is the Emission Intensity factor in $\mathrm{g} / \mathrm{kWh}$ for the production of electricity.

The Toyota Prius considered in this work is not a plug-in vehicle, therefore there was no electric consumption associated with the mission and the battery was continuously charged and discharged thanks to the presence of the engine (charge-sustaining strategy). For the Nissan Leaf, the electric consumption per $\mathrm{km}$ was corrected to take to account the circuity factor. The same values of $E I$ and charge efficiency of the aerial vehicle are used in this case:

$$
\mathrm{CO}_{2} \text {, elec, road }=\mathrm{EI} \cdot \mathrm{CF} \cdot \frac{E \mathrm{C}}{100 \cdot \eta_{\text {charge }}}
$$

where $E C$ is the electric consumption expressed in $\mathrm{kWh} / 100 \mathrm{~km}$. 
For the emission intensity factor $E I$, a sensitivity study was conducted. In fact, even if electricity generation from renewable sources has significantly increased in the last years, most of the electric energy is currently produced from fossil fuels [46,47].

According to the European Energy Agency (EEA [48]), the greenhouse Emission Intensity for EU in 2019 is, on average, $275.0 \mathrm{~g} \mathrm{CO}_{2} / \mathrm{kWh}$ with a maximum of $891 \mathrm{~g} \mathrm{CO}_{2} / \mathrm{kWh}$ for Estonia and a minimum of $8 \mathrm{~g} \mathrm{CO}_{2} / \mathrm{kWh}$ for Sweden as shown in Figure $3 \mathrm{a}$, where the value for Italy is also shown. However, the greenhouse emission intensity is expected to be reduced significantly in the next future. In this investigation, we will consider the average value of $90 \mathrm{~g} \mathrm{CO}_{2 \mathrm{eq}} / \mathrm{kWh}$ as the projected value in 2035.

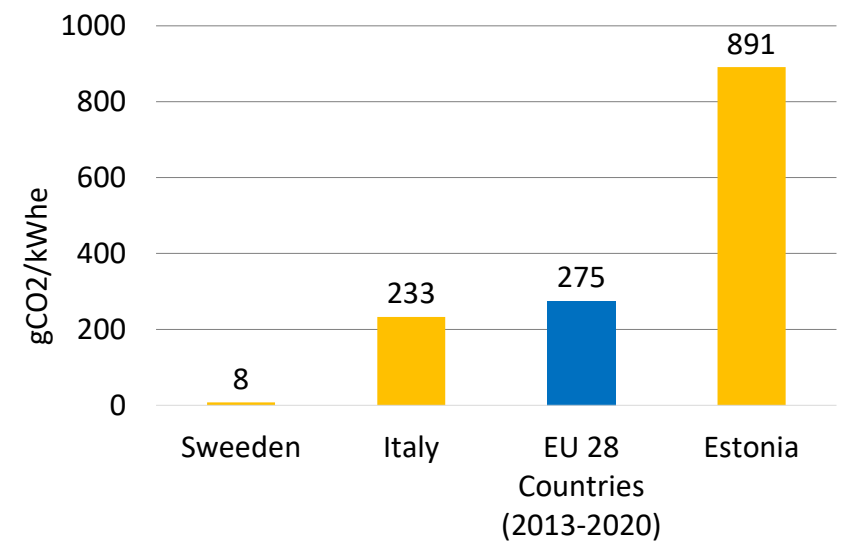

(a)

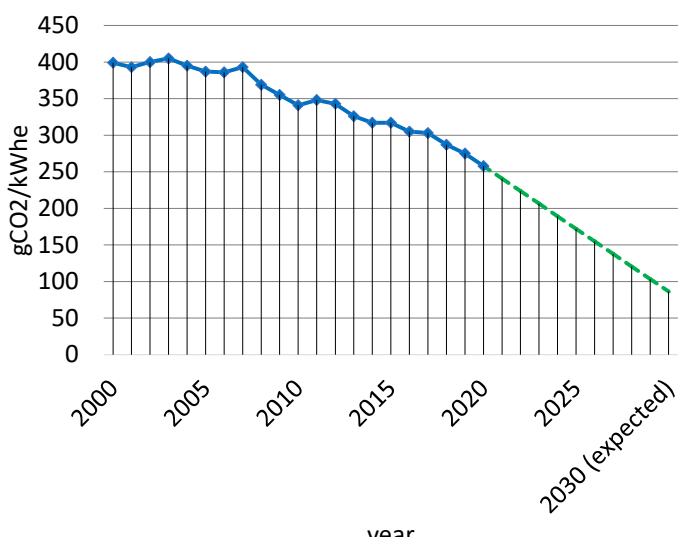

(b)

Figure 3. Past, present, and future emission intensity of European countries (elaboration of data from www.eea.europa.eu (accessed on 22 August 2021)). (a) Greenhouse Emission intensity in Europe (2019); (b) the trend of Greenhouse Emissions intensity vs. years (average value for EU 28 countries).

\section{Results}

The overall results of the proposed methodology are shown in Table 6 in terms of burn fuel $M_{f}$, electric consumption $E_{t o t}$, and battery DOD for the proposed configurations. Note that with today's technology, the overall energy consumption of the air taxi is very high for all the configurations but in particular for the full electric because of its very large mass.

Table 6. Burn fuel, electricity consumption, and battery DOD for the air taxi.

\begin{tabular}{|c|c|c|c|c|c|c|}
\hline & \multicolumn{3}{|c|}{ Today } & \multicolumn{3}{|c|}{2035} \\
\hline & $M_{f}(\mathrm{~kg})$ & $E_{t o t}(\mathrm{kWe})$ & DOD (\%) & $M_{f}(\mathrm{~kg})$ & $E_{t o t}(\mathrm{kWe})$ & DOD (\%) \\
\hline Conventional & 23.87 & - & - & 16.15 & - & - \\
\hline Hybrid ECMS & 21.46 & 14 & 40.06 & 9.77 & 14.05 & 40.04 \\
\hline $\begin{array}{c}\text { Hybrid } \\
\text { Rule-based }\end{array}$ & 21.6 & 13.04 & 37.16 & 13.5 & 7.5 & 21.4 \\
\hline Electric & - & 132.5 & 94.4 & - & 41.7 & 29.7 \\
\hline
\end{tabular}

Starting from conventional powertrains, we can see that with current and 2035 technology the fuel consumption is 34.1 and $23.1 \mathrm{~kg} / 100 \mathrm{~km}$, respectively. Such levels of consumption are very high when compared with those typical of the Toyota Prius.

For the hybrid solution, the consumption strongly depends on the energy management strategy because of the different power distribution, as shown in Figure 4. 

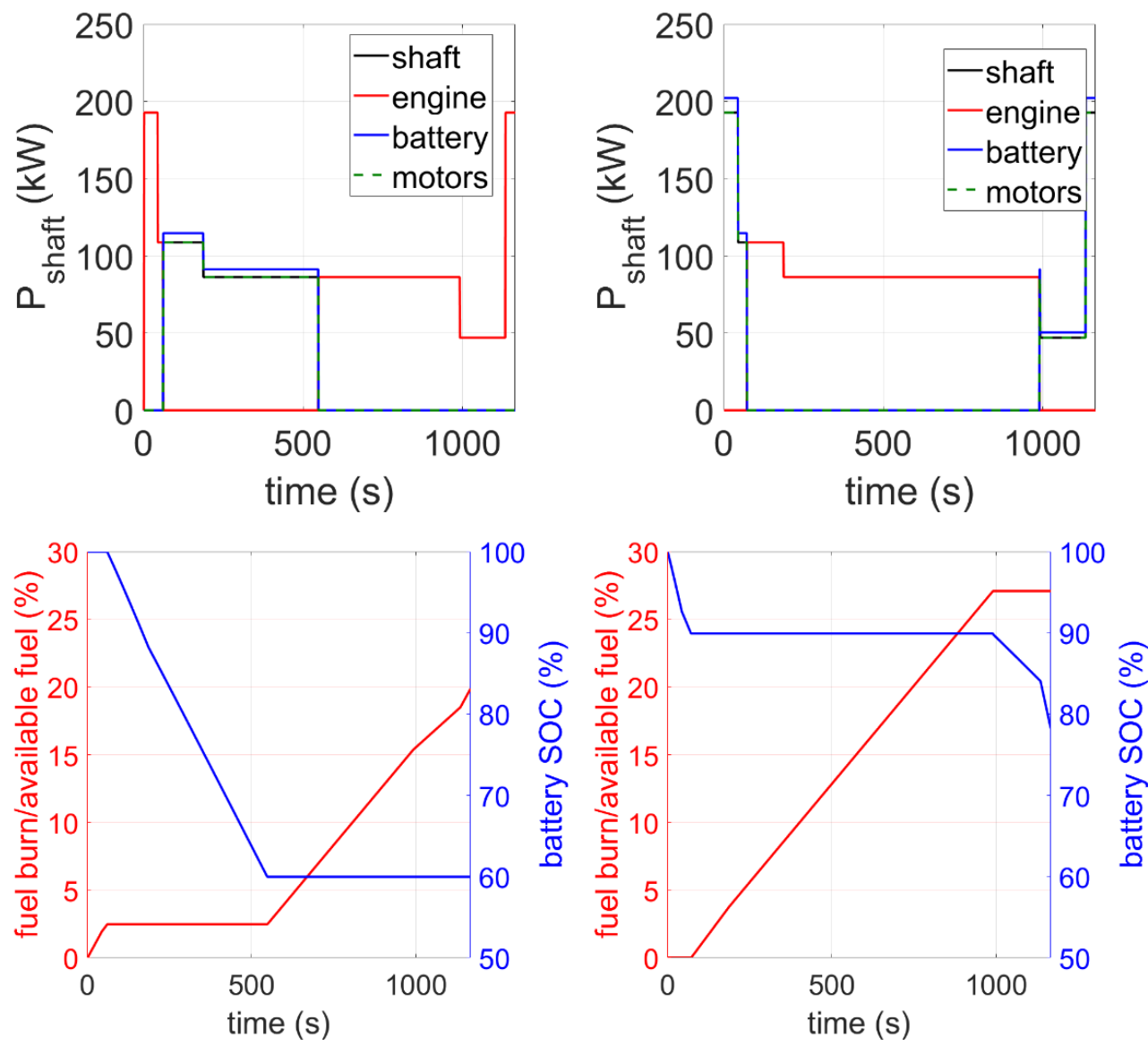

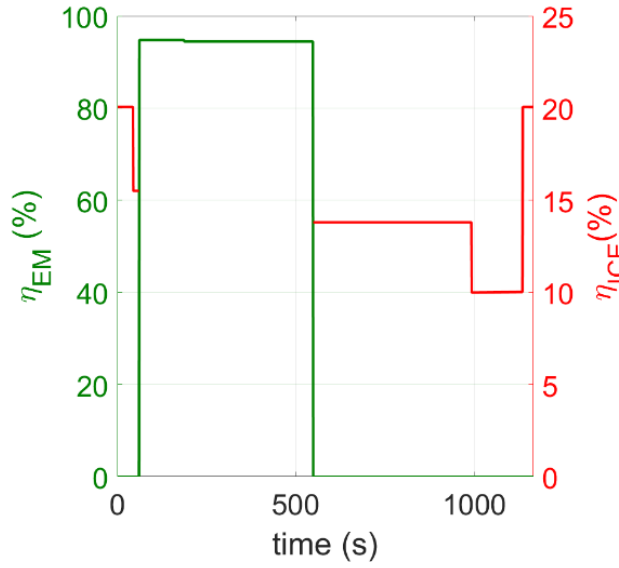

(a)

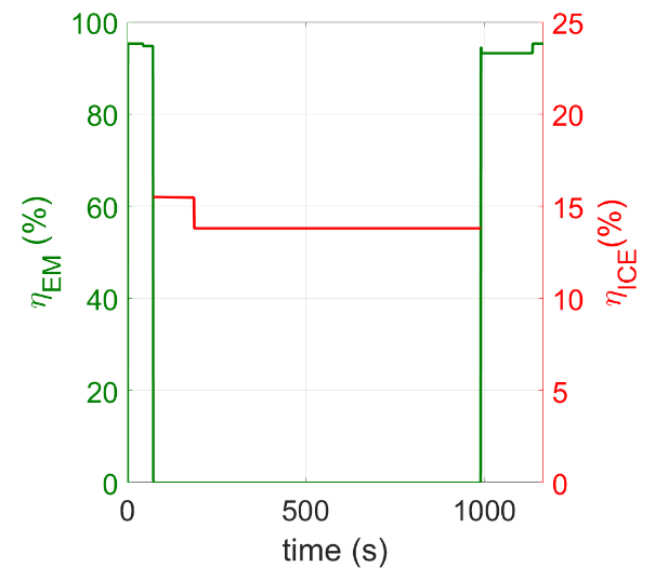

(b)

Figure 4. Power distribution, consumption, and efficiency time histories for the hybrid electric taxi with 2035 technology. (a) ECMS; (b) rule-based.

The ECMS strategy guarantees the best fuel economy because it allows the battery to be discharged up to the desired threshold of $60 \%$ at the end of the mission (for backup operation). With 2035 technology, the fuel consumption in the case of rule-based strategy is 38\% higher than that obtained with the ECMS while the electric consumption is $46.6 \%$ lower. The higher fuel consumption obtained with the rule-based strategy is mainly associated with the lower usage of the battery. However, the rule-based strategy guarantees a reduction i emissions at the road level because take-off, landing, and part of the climb are performed in electric mode (see Figure 4). Moreover, the lower DOD obtained with this strategy is advantageous in terms of both battery life and charging time between two 
consecutive flights. The bottom plots of Figure 4 show the efficiency curves of the motor and the engine in the two cases.

In the case of ECMS, engine efficiency is strongly dependent on the flight phases, like in a conventional aircraft. With the rule-based strategy, the engine is used only for cruise and part of the climb and is, therefore, quite oversized. This makes the engine work with an efficiency lower than $15 \%$ in the cruise phase. From a thermal efficiency point of view, it would be useful to choose a smaller engine or to select a different kind of thermal converter such as, for example, a piston engine. However, a smaller engine would not be able to perform take-off and landing in case of failure of the electric drive.

As for the electric powertrain, today's technology with the proposed size of the battery is not suitable for the mission considered in this study. In fact, the DOD is very high, and the electric consumption is $1.84 \mathrm{kWe} / \mathrm{km}$. The very high DOD is not only detrimental to the battery life and charge time but also does not allow reserve hover time. Note that at the moment there is no official regulation from aviation authorities about the reserve energy of the battery [12].

In the case of 2035 technology the electric consumption is reduced to $0.58 \mathrm{kWe} / \mathrm{km}$, which is still much higher than the value registered for the Nissan Leaf vehicle in the worst conditions $(0.24 \mathrm{kWe} / \mathrm{km})$. A smaller DOD could be obtained by choosing a larger battery. However, this would significantly increase the take-off weight of the fully electric vehicle according to the sizing procedure described in Section 2.

\subsection{WTW Analysis with Today Technology}

Figure 5 shows the WTW emissions of the air-taxi configurations with today's technology as a function of the Emission Intensity of electricity production. For simplicity, only the results with the rule-based strategy are reported for the hybrid electric vehicle. The best and worst cases related to the road taxi (Toyota Prius) were obtained with the following procedure.

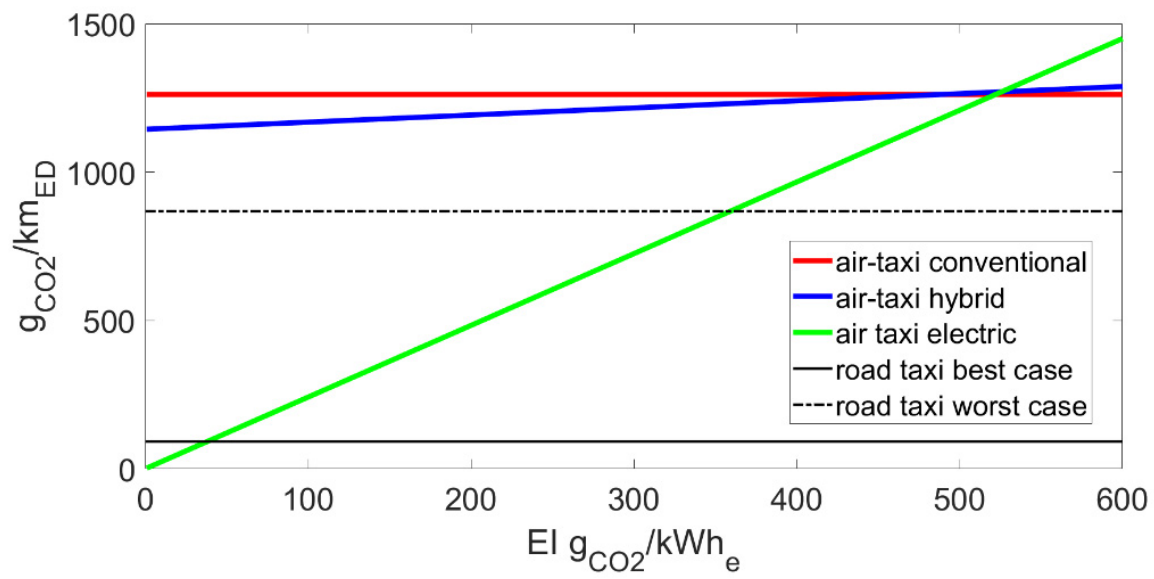

Figure 5. Comparison of WTW emissions of $\mathrm{CO}_{2}$ per km of Euclidean distance with today technology.

The circuity factor was increased from 1.1-2.1 [30] and Equation (17) was applied with the two values of fuel consumption $(3$ and $14.8 \mathrm{~L} / 100 \mathrm{~km})$ representative of the best and worst conditions of traffic and driving style for the Toyota Prius to obtain the plot of Figure 6. In the same plot, it was demonstrated that the WTW emissions of $\mathrm{CO}_{2}$ per km of Euclidean distance ranged in the interval $92-868 \mathrm{~g} / \mathrm{km}_{\mathrm{ED}}$. These are the values reported in Figure 5 as best and worst cases for the road vehicle. 


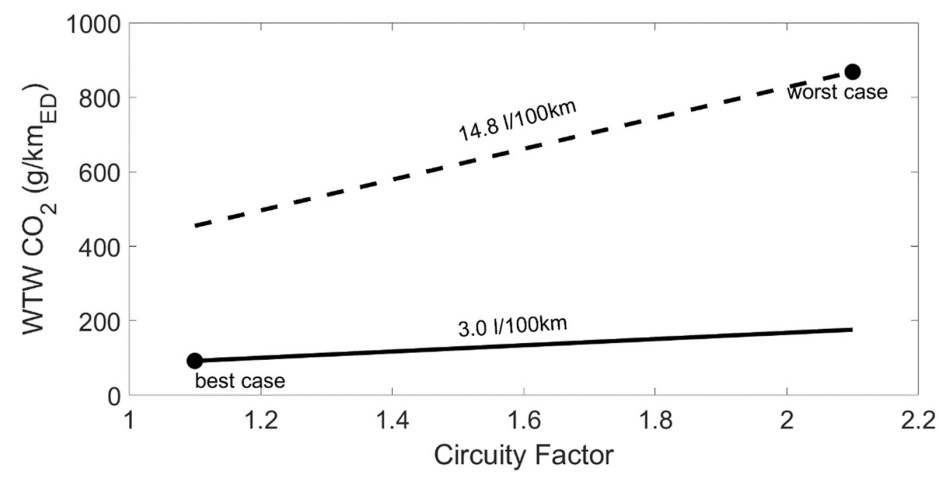

Figure 6. Equivalent WTW emissions of $\mathrm{CO}_{2}$ of the Prius as a function of circuity factor, traffic conditions, and driving style.

From the curve of Figure 5, we can notice that the air taxi with conventional or hybrid electric power systems generates levels of WTW emissions per $\mathrm{km}$ much higher than the road vehicles, even in the worst case. For the hybrid electric powertrain, the Emission Intensity of the electricity production has a weak effect on the overall values. The emissions of the full-electric air taxi are below those of the road vehicle under the best and worst driving conditions if the EI is below 40 and $360 \mathrm{~g} / \mathrm{kWe}$, respectively.

\subsection{WTW Analysis with 2035 Technology}

The final comparison with 2035 technology is shown in Figure 7. For the Nissan Leaf (road taxi) the best and worst cases were calculated with the following values: $24 \mathrm{kWh} / 100 \mathrm{~km}$ and a circuity factor of 2.1 as the worst case, $17 \mathrm{kWh} / 100 \mathrm{~km}$ and $\mathrm{CF}=1.1$ as the best case.

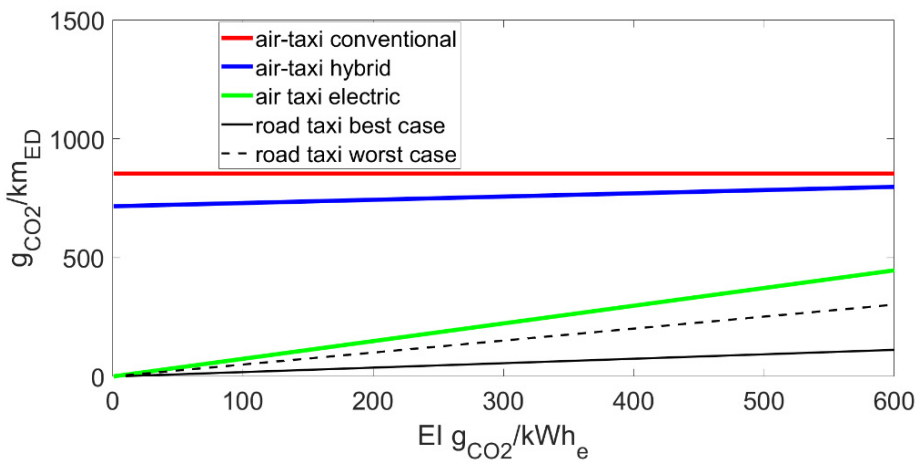

Figure 7. Comparison of WTW emissions of $\mathrm{CO}_{2}$ per km of Euclidean distance with 2035 technology.

Even in the worst conditions, the electric road taxi is advantageous over the air taxi in terms of overall WTW emissions of $\mathrm{CO}_{2}$ per kmED.

The WTW emissions with the expected Emission Intensity of $90 \mathrm{~g} / \mathrm{kWe}$ for the European Union in 2035 are quite low $(67 \mathrm{~g} / \mathrm{km})$ for the full electric air taxi. Moreover, if all road taxis would be replaced by aerial vehicles, there would be a significant improvement in the traffic level with positive effects on the consumption and emissions of the whole road fleet.

Note that the two electric vehicles (road and electric air taxi with 2035 technology) have about the same mass (curb + payload) but the power demand of the aerial vehicle is much higher because of the very high cruise speed $(240 \mathrm{~km} / \mathrm{h})$. As a consequence, the flight time is about $20 \mathrm{~min}$ while the road taxi would take from 1 to $2.5 \mathrm{~h}$ according to the traffic conditions with a circuity factor of 1.28 [11,49].

To understand the corrective measures to be taken to reduce the unfavorability of aerial vs. road vehicles, it is sufficient to analyze the terms in Equation (3) since the cruise 
is the most relevant flight phase in terms of energy consumption. For the road vehicle, the power request at the wheel at constant speed $\mathrm{V}$ and no road grade can be calculated as:

$$
P_{\text {wheel }}=\frac{1}{2} c_{d} A_{f} \rho_{a} V^{3}+c_{r} M g V
$$

where $c_{d}$ is the aerodynamic coefficient, $A_{f}$ is the frontal area of the vehicle, $c_{r}$ is the rolling friction coefficient, and $\rho_{a}$ is the ambient air density. Assuming the same mass of $1800 \mathrm{~kg}$ for each vehicle and suitable values of $c_{d} A_{f}\left(0.7 \mathrm{~m}^{2}\right)$ and $c_{r}(0.012)$ for a full-sized vehicle [26], the power request of the road vehicle is shown in Figure 8 and compared with those of the air taxi at the same speed (calculated from Equation (3)). Note that the road taxi power is lower than that of the aerial vehicle up to about $210 \mathrm{~km} / \mathrm{h}$, which is, however, too high a speed for a road vehicle. Moreover, improvement in $c_{d} A_{f}$ and $c_{r}$ can be expected in the future for road vehicles that would further reduce the energy request of these vehicles.

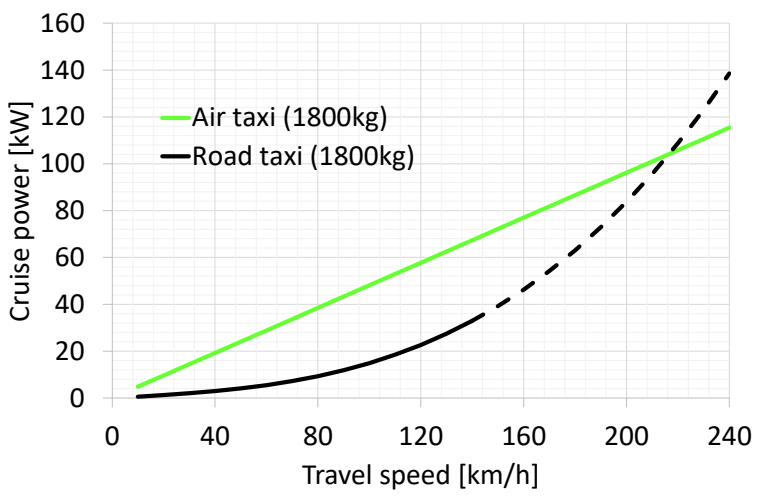

Figure 8. Cruise power vs. travel speed for an air vehicle and a road taxi with the same mass.

For the aerial vehicle, the cruise power is equally influenced by $L / D$ and propulsive efficiency so a strong improvement of one or more of these parameters would be needed to reduce the energy consumption at constant cruise speed.

\subsection{Effect of Battery Aging}

The results shown in the previous section were obtained with a battery at the start of its life. If the battery-aging phenomena were considered, the same trip would require more electricity to charge the battery (because the battery would be discharged faster) and the battery would not be able to sustain the selected mission (in particular in the case of the electric vehicle with today's technology).

To take into account the effect of battery aging, the energy consumption of the hybrid electric and electric power systems with 2035 technology was recalculated with the battery at the end of its life (equivalent to 400 full discharge-recharge cycles). The results are shown in Table 7 . For the hybrid electric case, only the results with the rule-based strategy are shown in Figure 9. We noticed that the aging of the battery determined a slight increase in fuel consumption $(+1.5 \%)$ because of the rules used during the climb. In fact, in this phase of the flight, the battery is used until its SOC reaches the value of $90 \%$. In the case of the aged battery, this threshold is reached at the end of take-off so the climb is performed only in thermal mode. Because of the reduced capacity, increased internal resistance, and increased Peukert coefficient, the electric consumption is 12 and 27\% higher for the hybridelectric and electric configuration, respectively. The DOD is also significantly increased in both cases with a reduction in the number of consecutive missions that the vehicle can perform before fully charging the battery. The DOD affects the charging time between two subsequent flights, which also depends on the charging current. Rapid charging introduces problems in terms of charging cost, reduces the battery life, and compromises the energy density (because there is a tradeoff between energy density and power density in the design of the batteries, as already explained). 
Table 7. Effect of battery aging of consumption (with 2035 technology, rule-based strategy for the hybrid power system).

\begin{tabular}{lcccccc}
\hline & \multicolumn{3}{c}{ New Battery } & \multicolumn{3}{c}{ Aged Battery } \\
\cline { 2 - 6 } & $\begin{array}{c}\text { Burn Fuel } \\
\mathbf{( k g )}\end{array}$ & $\begin{array}{c}\text { Electricity } \\
\mathbf{( k W e )}\end{array}$ & DOD (\%) & $\begin{array}{c}\text { Burn Fuel } \\
\mathbf{( k g )}\end{array}$ & $\begin{array}{c}\text { Electricity } \\
(\mathbf{k W e})\end{array}$ & DOD (\%) \\
\hline Hybrid & 13.5 & 7.5 & 21.4 & $\begin{array}{c}14.04 \\
(+1.5 \%)\end{array}$ & $9.5(+12 \%)$ & 27.0 \\
Electric & - & 41.7 & 29.7 & - & $\begin{array}{c}52.9 \\
(+27 \%)\end{array}$ & 37.7 \\
\hline
\end{tabular}
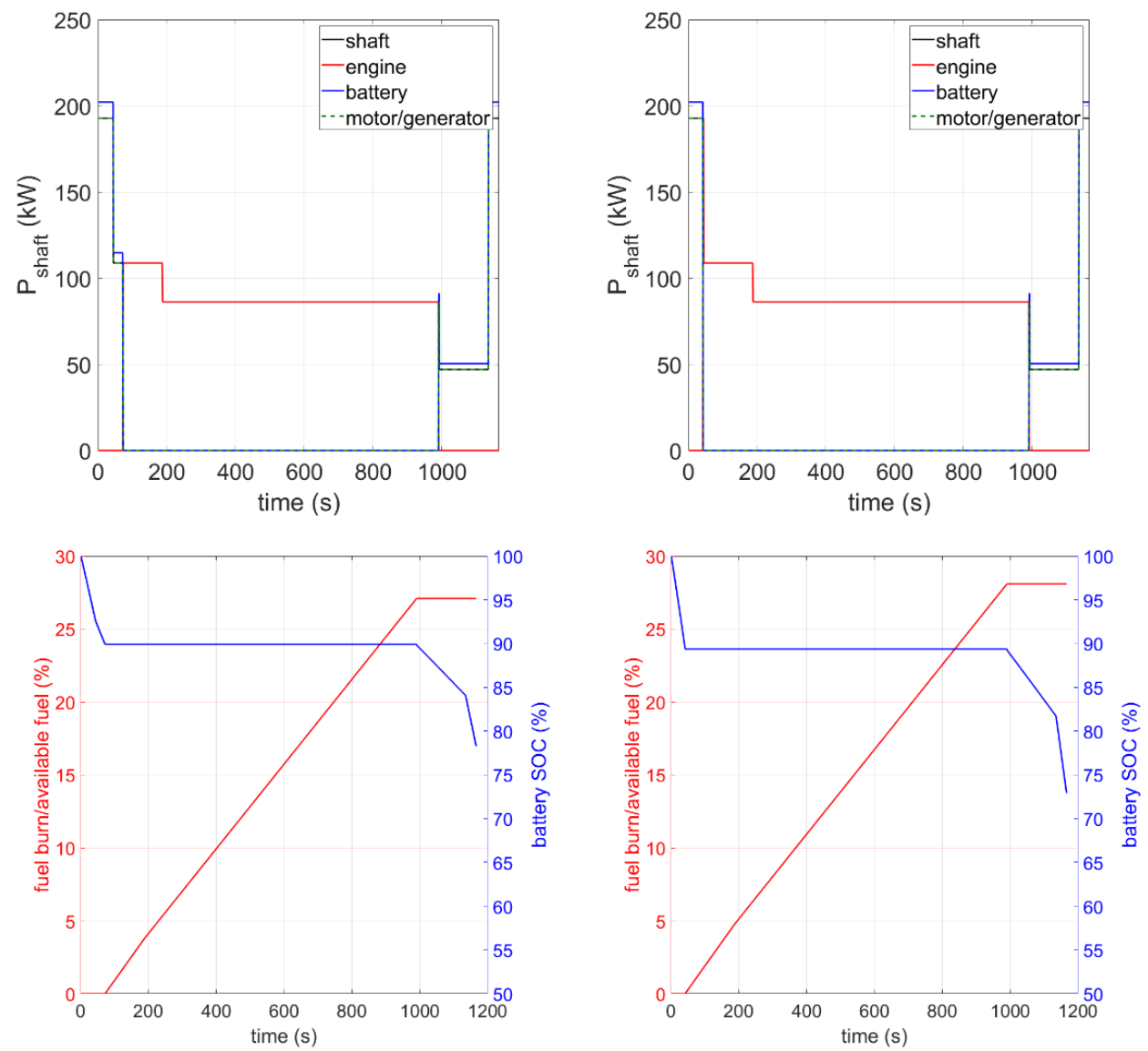

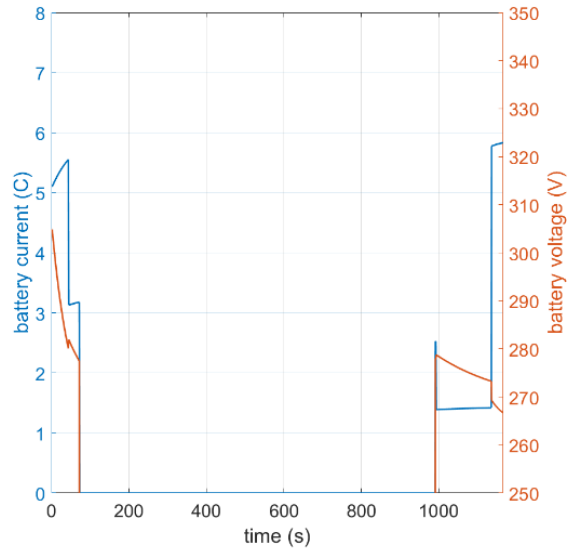

(a)

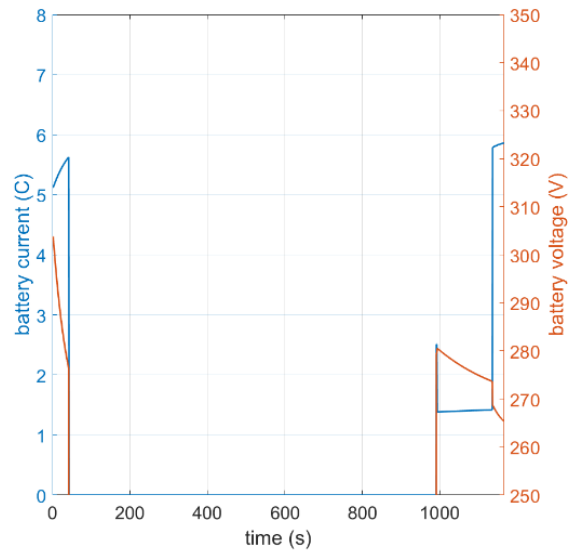

(b)

Figure 9. Effect of battery aging on the behavior of the hybrid electric air taxi (the hybrid electric taxi with 2035 technology). (a) new battery; (b) aged battery. 
For a fully electric taxi, Uber [11] suggests that the vehicle should be operated continuously for at least $3 \mathrm{~h}$ without reaching the minimum reserve state of charge $(30 \%)$ and with a $7 \mathrm{~min}$ recharge between each flight to partially recharge the battery. To do this, Uber suggests limiting the DOD in each mission and partially charging the battery between each mission. This approach was used here to estimate the number of consecutive missions with different levels of charging between them. This quantity was denoted as DOC (Depth of Charging) and varied between 0 (no charge) and 20\%, meaning that the initial state of charge for a mission was set equal to the final SOC of the previous mission plus DOC. The simulation ended when the SOC reached the threshold of $20 \%$. The procedure is illustrated in Figure 10 with specific reference to the electric air taxi with 2035 technology and the battery at the beginning of its life. The arrow in the Figure 10 explains the concept of DOC. The results obtained in the other cases are shown in Table 8. Note that the higher the DOC, the longer the charging time between two missions. The estimation of the charging time was not performed in this investigation because it is not relevant to the goal of this investigation.

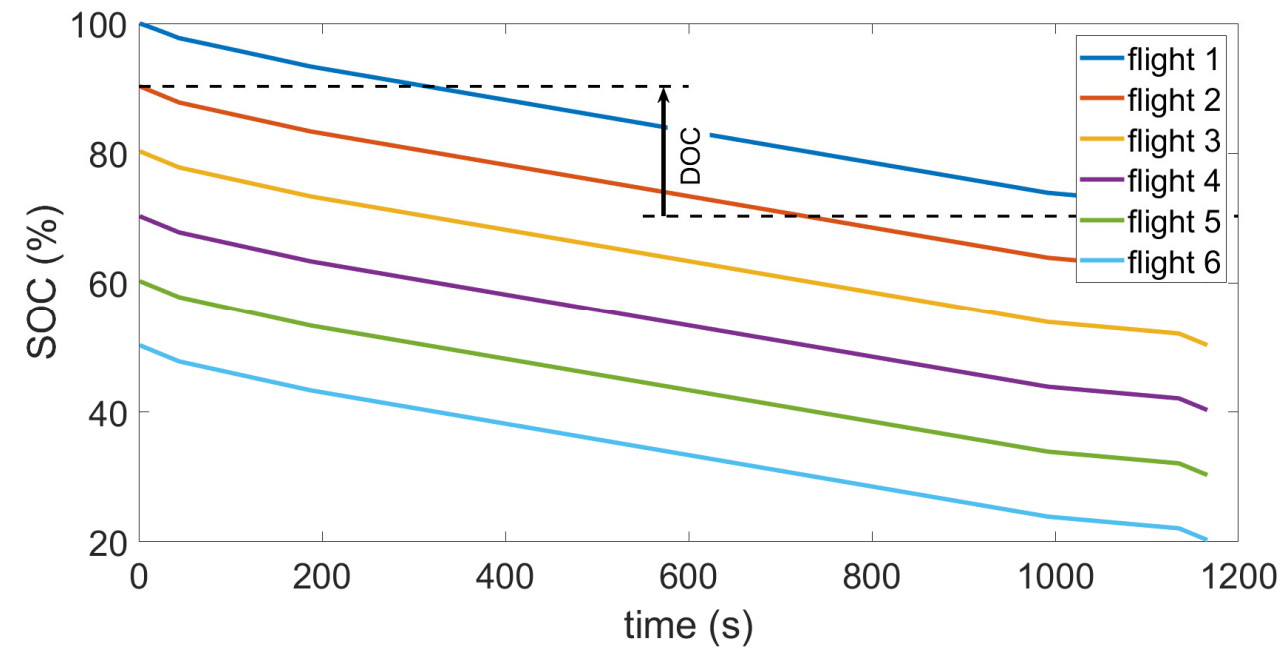

Figure 10. Repeated flights with DOC $=20 \%$ for the electric air-taxi with 2035 technology and new battery. The arrow shows the increment of charge (DOC) between the end of flight 1 and the beginning of flight 2 .

Table 8. Effect of battery aging on the number of consecutive flights.

\begin{tabular}{ccccccc}
\hline & \multicolumn{3}{c}{ New Battery } & \multicolumn{3}{c}{ Aged Battery } \\
\cline { 2 - 7 } & DOC $=\mathbf{0} \%$ & DOC $=\mathbf{1 0} \%$ & DOC $=\mathbf{2 0} \%$ & DOC $=\mathbf{0} \%$ & DOC $=\mathbf{1 0} \%$ & DOC $=\mathbf{2 0} \%$ \\
\hline Hybrid & 3 & 7 & $($ DOD $=$ DOC $)$ & 2 & 3 & 7 \\
Electric & 2 & 3 & 6 & 2 & 2 & 3 \\
\hline
\end{tabular}

In the case of a hybrid-electric vehicle with a DOD of $20 \%$ and a new battery, the vehicle can operate continuously because the DOD is almost equal to the DOC, while in the case of an aged battery it is possible to perform seven consecutive flights. For the fully electric vehicle, the continuous flight is obtained with DOC $=29.7 \%$ when the battery is at the beginning of its life.

The number of consecutive flights without full charge is very limited (two) in the case of DOC = zero, i.e., without intermediate partial charging for both the hybrid and the electric aerial taxis.

\section{Summary and Conclusions}

A new and detailed methodology was developed to analyze the performance of conventional, hybrid electric, and full-electric air taxis and to compare their environmental 
impact with road taxis performing the same route. The novel contribution to the state of the art is in the detailed modeling approach of the powertrains, the evaluation of $\mathrm{CO}_{2}$ emissions with a Well-to- Wing approach as a function of the electricity Emission Intensity factor, and the comparison with road vehicles performing the same route in different driving conditions.

In particular, the air taxis were designed according to current and 2035 technology and modeled with an in-house simulation tool. The proposed simulation approach computes the off-design efficiencies of the engine and motor during the mission and accounts for battery non-linear discharge effects (such as the Peukert dependence of capacity from discharge current) and aging phenomena. In the case of the hybrid-electric air taxi, two different energy management strategies were considered and compared.

Reference vehicles were selected for comparison with road taxis and literature values were assumed for the consumption of these vehicles in real driving conditions. The comparison demonstrated the advantages of the electrified air taxi with today's technology over a hybrid-electric road taxi, especially in the case of low emission intensity of the electricity production and penalizing boundary conditions (congested traffic, aggressive driving style, and high values of circuity factor). In the case of 2035 technology, the comparison with a fully electric road vehicle was unfavorable but the WTW emissions with the expected Emission Intensity of $90 \mathrm{~g} / \mathrm{kWe}$ for the European Union in 2035 were quite low $(67 \mathrm{~g} / \mathrm{km})$. Note that these results could be interpolated for a reasonable estimation of the energy consumption and $\mathrm{CO}_{2}$ emissions with short-term improvement (such as, for example, 2025 technologies).

The results of the simulation performed with the aged battery underlined the negative effect of this phenomenon on the consumption of the air taxi and on the number of consecutive flights that can be performed with fast intermediate charging of the battery. These results stress the importance of improving the battery technology not only in terms of power and energy density but also in terms of calendar and cycle life to enhance the usage of electrified propulsion systems as an air-taxi service. In future work, the authors will tackle the development of a dynamic model of the hybrid electric power system to account for the shaft dynamic of the rotorcraft and the transient behavior of the fuel system of the turboshaft engine.

Author Contributions: Conceptualization, T.D. and A.F.; methodology, T.D.; writing-original draft preparation, T.D.; writing-review and editing, T.D. and A.F. All authors have read and agreed to the published version of the manuscript.

Funding: This research received no external funding.

Conflicts of Interest: The authors declare no conflict of interest.

\section{Abbreviations}

$\begin{array}{ll}\text { CF } & \text { Circuity Factor } \\ \text { DOC } & \text { Depth of intermediate Charge } \\ \text { DOD } & \text { Depth Of Discharge } \\ \text { EC } & \text { Electric consumption of the plug-in vehicle in } \mathrm{kWh} / 100 \mathrm{~km} \\ \text { ECMS } & \text { Equivalent Consumption Minimization Strategy } \\ \text { ED } & \text { Euclidean distance } \\ \text { EEA } & \text { European Energy Agency } \\ \text { EI } & \text { Emission intensity of the electricity production system } \\ \text { eVTOL } & \text { Electric Vertical Take-off and Landing } \\ \text { FC } & \text { Fuel consumption of the road vehicle in liter } / 100 \mathrm{~km} \\ \text { GHG } & \text { Greenhouse Gas } \\ \text { TTW } & \text { Tank-To-Wheel/Wing } \\ \text { UAM } & \text { Urban Air Mobility }\end{array}$




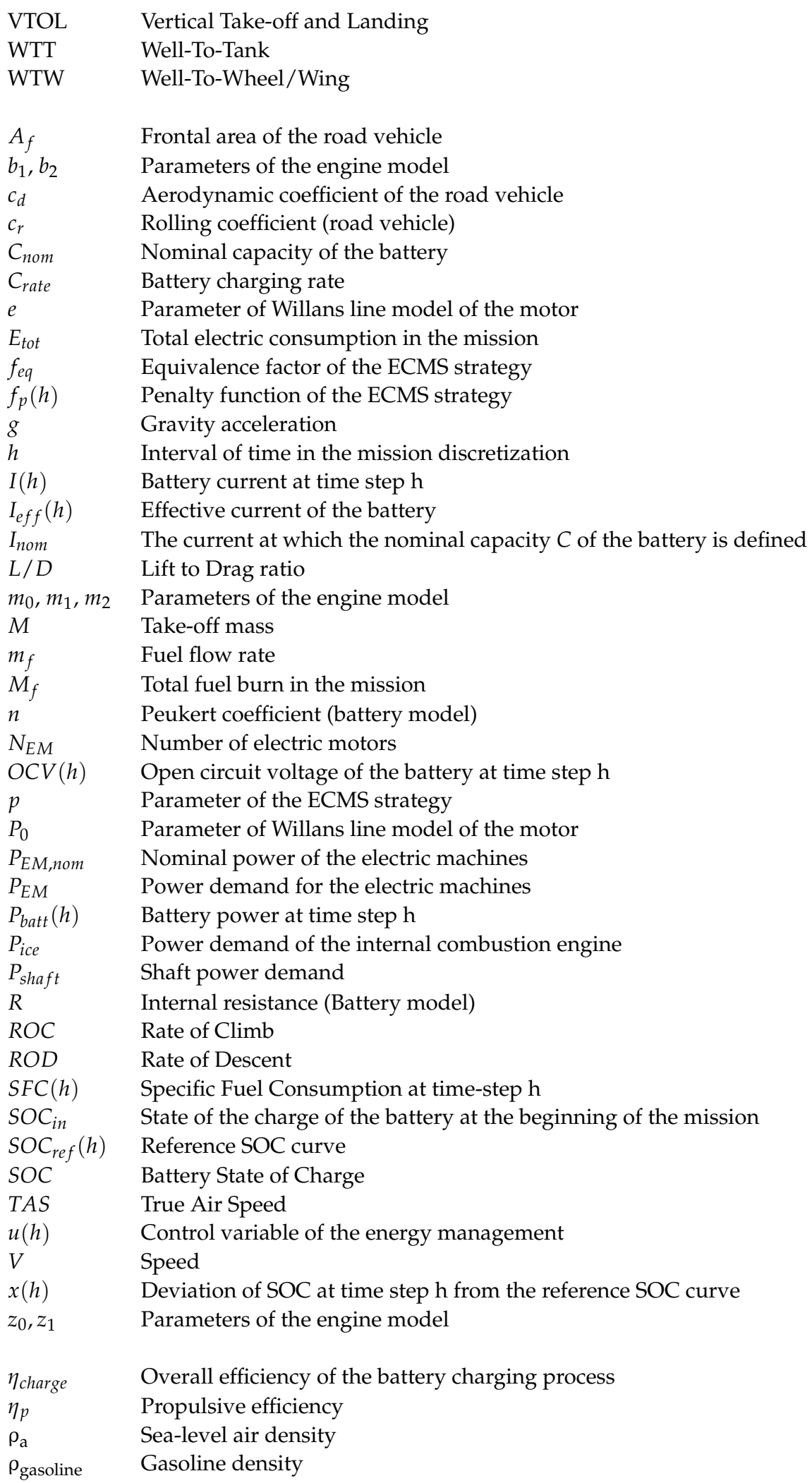




\section{Appendix A}

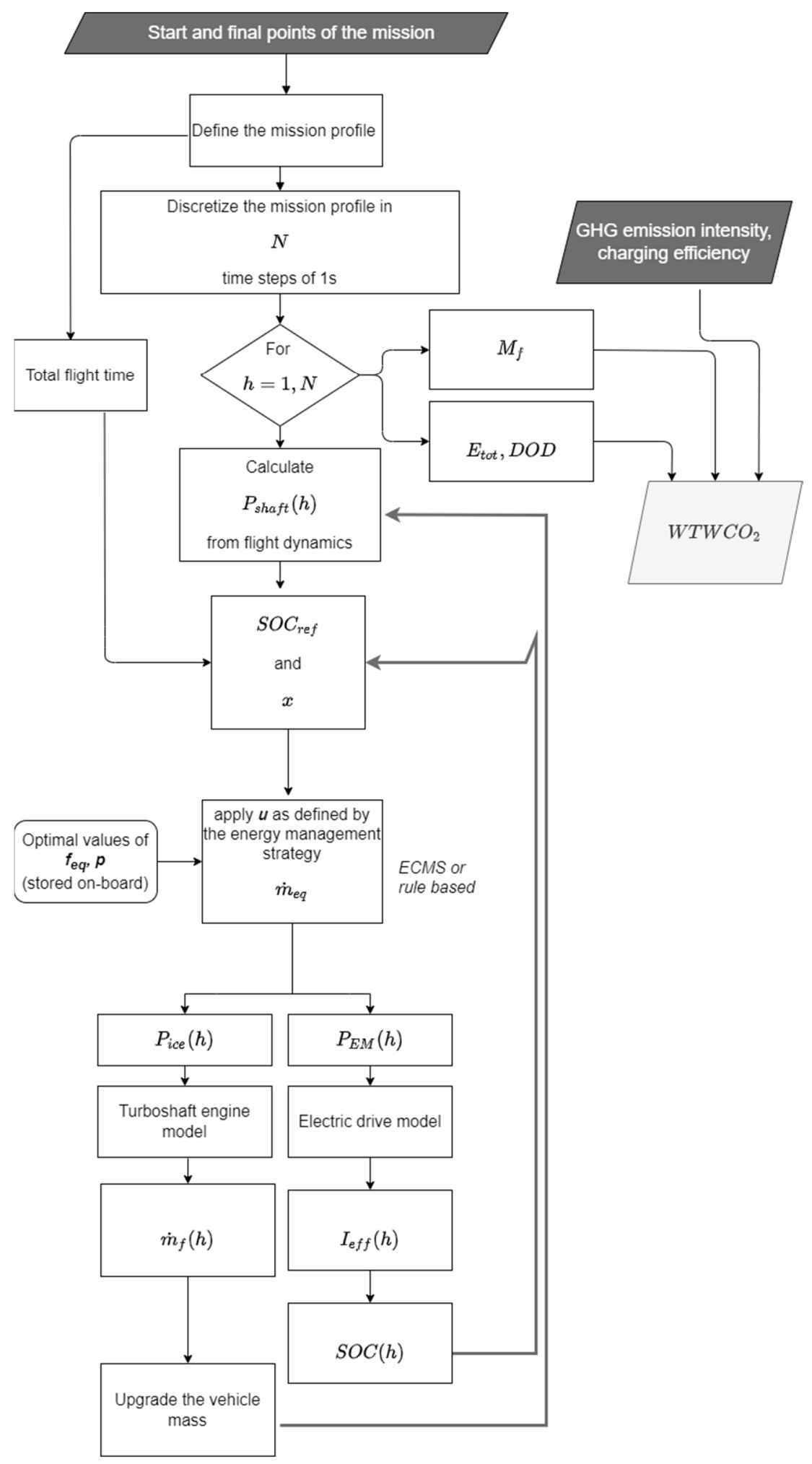

Figure A1. Flowchart of the proposed procedure. 


\section{References}

1. Angel, S.; Parent, J.; Civco, D.L.; Blei, A.M. Making Room for a Planet of Cities; Lincoln Institute of Land Policy: Cambridge, MA, USA, 2011; ISBN 978-1-55844-212-2.

2. Papadopoulos, E.; Aggelakakis, A.; Tromaras, A. The Future of the European Transport Sector: Identifying the Key Trends Regarding the Transport Concepts of the Future. In Proceedings of the International Conference on Traffic and Transport Engineering-ICTTE, Belgrade, Serbia, 27 September 2018.

3. A European Strategy for Low-Emission Mobility. Available online: https://ec.europa.eu/commission/presscorner/detail/en/ MEMO_16_2497 (accessed on 22 August 2021).

4. Malaud, F. Urban Air Mobility: Is This a Different Way of Saying “Aviation in Cities"? Available online: https://unitingaviation. $\mathrm{com} /$ news/safety/urban-air-mobility-is-this-a-different-way-of-saying-aviation-in-cities/ (accessed on 9 March 2021).

5. Galindo, A. Detect-and-Avoid (DAA): How Airborne Collision Avoidance Works. Available online: https://www.irisonboard. com/detect-and-avoid-how-airborne-collision-avoidance-works /\#: \{\}:text=However\%2C\%20the \%20majority\%20of\%20 manned,commonly\%20flown\%20at\%20low\%20altitudes (accessed on 10 March 2021).

6. Honeywell International Inc. Autonomy and Avionics for Urban Air Mobility. Available online: https://aerospace.honeywell com/en/learn/products/navigation-and-radios/autonomy-and-avionics-for-urban-air-mobility (accessed on 10 March 2021).

7. Electric Propulsion for a Disruptive Mobility Concept. Available online: https://www.rolls-royce.com/products-and-services / electrical/propulsion/air-taxis.aspx (accessed on 10 August 2021).

8. Goodchild, A.; Toy, J. Delivery by drone: An evaluation of unmanned aerial vehicle technology in reducing $\mathrm{CO}_{2}$ emissions in the delivery service industry. Transp. Res. Part D 2018, 61, 58-67. [CrossRef]

9. Kirschstein, T. Comparison of energy demands of drone-based and ground-based parcel delivery services. Transp. Res. Part D Transp. Environ. 2020, 78, 102209. [CrossRef]

10. Zhang, J.; Campbell, J.F.; Sweeney, D.C.; Hupman, A.C. Energy consumption models for delivery drones: A comparison and assessment. Transp. Res. Part D Transp. Environ. 2021, 90, 102668. [CrossRef]

11. Uber Elevate. Uber Air Vehicle Requirements and Missions. Available online: https://s3.amazonaws.com/uber-static/elevate/ Summary+Mission+and+Requirements.pdf (accessed on 22 August 2021).

12. Uber. Uber Elevate: Fast Forwarding to a Future of On-Demand Urban Air Transportation. 2016. Available online: https: / / www.uber.com/elevate.pdf (accessed on 22 August 2021).

13. Kasliwan, A.; Furbush, N.J.; Grawron, J.H.; McBride, J.R.; Wallington, T.J.; De Kleine, R.D.; Kim, H.C.; Keoleian, G.A. Role of flying cars in sustainable mobility. Nat. Commun. 2019, 10, 1555. [CrossRef]

14. Johnson, W.; Silva, C.; Solis, E. Concept Vehicles for VTOL Air Taxi Operations. In Proceedings of the AHS Technical Conference on Aeromechanics Design for Transformative Vertical Flight, San Francisco, CA, USA, 16-19 January 2018.

15. Garrow, L.A.; German, B.J.; Leonard, C.E. Urban air mobility: A comprehensive review and comparative analysis with autonomous and electric ground transportation for informing future research. Transp. Res. Part C 2021, 132, 103377. [CrossRef]

16. Mudumba, S.V.; Chao, H.; Maheshwari, A.; DeLaurentis, D.A.; Crossley, W.A. Modeling $\mathrm{CO}_{2}$ Emissions from Trips using Urban Air Mobility and Emerging Automobile Technologies. Transp. Res. Rec. 2021, 2675, 1237-1244. [CrossRef]

17. Datta, A. Commercial Intra-City On-Demand Electric-VTOL Working Report; Vertical Flight Society: Fairfax, VA, USA, 2018.

18. Snyder, C.A.; Tong, M.T. Modeling Turboshaft Engines for the Revolutionary Vertical Lift Technology Project. In Proceedings of the American Helicopter Society 75th Annual Forum, Philadelphia, PA, USA, 13-16 May 2019.

19. GE Turbines and Small Engines Overview. Available online: https://arpa-e.energy.gov/sites/default/files/14_deBock_GE\%20 Turbines\%20and\%20small\%20engines\%20overview\%20-\%20ARPA-e\%20INTEGRATE\%20V2.pdf (accessed on 3 November 2021).

20. Bérubé, D.; Dessaint, L.A.; Liscouet-Hanke, S.; Lavoie, C. Simulation of a hybrid emergency power system for more electric aircraft. Can. Aeronaut. Space J. 2011, 57, 155-162. [CrossRef]

21. Donateo, T.; Spedicato, L. Fuel economy of hybrid electric flight. Appl. Energy 2017, 206, 723-738. [CrossRef]

22. Hill Helicopters Reveals New Turboshaft Engine. Available online: https://www.flyer.co.uk/hill-helicopters-reveals-newturboshaft-engine (accessed on 22 August 2021).

23. Knight, H. Airbus and Siemens Investigate Hybrid-Electric Propulsion Systems for Low Emission Aviation. 18 April 2016. Available online: https:/ / www.theengineer.co.uk/airbus-and-siemens-investigate-hybrid-electric-propulsion-for-low-emissionaviation/ (accessed on 31 August 2021).

24. Lipol Battery. Available online: www.lipolbattery.com (accessed on 3 February 2017).

25. Cole, J.A.; Rajauski, L.; Loughran, A.; Karpowicz, A.; Salinger, S. Configuration Study of Electric Helicopters for Urban Air Mobility. Aerospace 2021, 8, 54. [CrossRef]

26. Guzzella, L.; Sciarretta, A. Vehicle Propulsion Systems: Introduction to Modeling and Optimization; Springer: Berlin, Germany, 2007.

27. Johnson, W.; Silva, C.; Solis, E. NASA concept vehicles and the engineering of advanced air mobility aircraft. Aeronaut. J. 2022, 126, 59-91. [CrossRef]

28. Park, Y.-K.; Moon, S.-W.; Kim, T.-S. Advanced Control to Improve the Ramp-Rate of a Gas Turbine: Optimization of Control Schedule. Energies 2021, 14, 8024. [CrossRef]

29. Donateo, T.; Spada Chiodo, L.; Ficarella, A. Transient behavior of a hybrid electric air-taxi. In Proceedings of the International Symposium on Sustainable Aviation, Bangkok, Thailand, 25-27 November 2021. 
30. Ballou, R.H.; Rahardja, H.; Sakai, N. Selected country circuity factors for road travel distance estimation. Trans. Res. Part A Policy Pract. 2002, 36, 843-848. [CrossRef]

31. Donateo, T.; Ficarella, A. Off-line and On-line Optimization of the Energy Management Strategy in a Hybrid Electric Helicopter for Urban Air-Mobility. Aerosp. Sci. Technol. 2021, 113, 106677. [CrossRef]

32. Donateo, T.; Ficarella, A. A Modeling Approach for the Effect of Battery Aging on the Performance of a Hybrid Electric Rotorcraft for Urban Air-Mobility. Aerospace 2020, 7, 56. [CrossRef]

33. Hoke, A.; Brissette, A.; Maksimović, D.; Pratt, A.; Smith, K. Electric vehicle charge optimization including effects of lithium-ion battery degradation. In Proceedings of the 2011 IEEE Vehicle Power and Propulsion Conference, Chicago, IL, USA, 6-9 September 2011; pp. 1-8. [CrossRef]

34. Fares, R.L.; Webber, M.E. What are the tradeoffs between battery energy storage cycle life and calendar life in the energy arbitrage application? J. Energy Storage 2018, 12, 37-45. [CrossRef]

35. Millner, A. Modeling Lithium Ion battery degradation in electric vehicles. In Proceedings of the 2010 IEEE Conference on Innovative Technologies for an Efficient and Reliable Electricity Supply, Waltham, MA, USA, 27-29 September 2010; pp. 349-356. [CrossRef]

36. Li, J.; Gee, A.M.; Zhang, M.; Yuan, W. Analysis of battery lifetime extension in a SMES-battery hybrid energy storage system using a novel battery lifetime model. Energy 2015, 86, 175-185. [CrossRef]

37. Zeng, X.-H.; Wang, Q.; Wang, Q.-N. Simulation and analysis of THS II based on ADVISOR software. In Proceedings of the ICCASM 2010, International Conference on Computer Application and System Modeling, Taiyuan, China, 22-24 October 2010; Volume 5, pp. V5131-V5136. [CrossRef]

38. Fontanas, G.; Pistikopoulos, P.; Samaras, Z. Experimental evaluation of hybrid vehicle fuel economy and pollutant emissions over real-world simulation driving cycles. Atmos. Environ. 2008, 42, 4023-4035. [CrossRef]

39. Pitanuwat, S.; Sripakagorn, A. An Investigation of Fuel Economy Potential of Hybrid Vehicles under Real-World Driving Conditions in Bangkok. Energy Procedia 2015, 79, 1046-1053. [CrossRef]

40. Nissan Leaf Taxi. Available online: https:/ / www.greencarreports.com/news/nissan-leaf-taxi (accessed on 27 October 2021).

41. Electric Vehicle Database. Available online: https://ev-database.org/car/ (accessed on 27 October 2021).

42. Donateo, T.; Ingrosso, F.; Bruno, D.; Laforgia, D. Effect of driving conditions and auxiliaries on mileage and $\mathrm{CO}_{2}$ emissions of a gasoline and an electric city car. SAE Tech. Pap. 2014, 1, 1-13. [CrossRef]

43. Gan, L.; Topcu, U.; Low, S. Optimal decentralized protocol for electric vehicle charging. In Proceedings of the 201150 th IEEE Conference on Decision and Control and European Control Conference (CDC-ECC), Orlando, FL, USA, 12-15 December 2011.

44. Thiel, C.; Schmidt, J.; Van Zyl, A.; Schmid, E. Cost and well-to-wheel implications of the vehicle fleet $\mathrm{CO}_{2}$ emission regulation in the European Union. Transp. Res. Part A 2014, 63, 25-42. [CrossRef]

45. Donateo, T.; Ingrosso, F.; Licci, F.; Laforgia, D. A method to Estimate the Environmental Impact of an Electric City Car during Six Months of Testing in an Italian City. J. Power Sources 2014, 270, 487-498. [CrossRef]

46. Ang, B.W.; Su, B. Carbon emission intensity in electricity production: A global analysis. Energy Policy 2016, 94, 56-63. [CrossRef]

47. Cerdeira Bento, J.P.; Moutinho, V. $\mathrm{CO}_{2}$ emissions, non-renewable and renewable electricity production, economic growth, and international trade in Italy. Renew. Sustain. Energy Rev. 2016, 55, 142-155. [CrossRef]

48. European Environment Agency. Available online: https://www.eea.europa.eu/ (accessed on 23 August 2021).

49. Donateo, T.; Ficarella, A.; Surdo, L. Energy consumption and environmental impact of Urban Air Mobility. In Proceedings of the 11th Easn Virtual International Conference on Innovation in Aviation \& Space to the Satisfaction of the European Citizens, Salerno, Italy, 1-3 September 2021. 